\title{
1,3-Thiazolium-5-thiolates Mesoionic Compounds: Semiempirical Evaluation of their First Static Hyperpolarizabilities and Synthesis of New Examples
}

\author{
Bruno F. Lyra, ${ }^{a, b}$ Soraya A. de Morais, ${ }^{a}$ Gerd B. Rocha, ${ }^{*, a}$ Joseph Miller, ${ }^{b, c, t}$ \\ Gustavo L. C. Moura, ${ }^{c}$ Alfredo M. Simas, ${ }^{c}$ Clovis Peppe ${ }^{d}$ and Petrônio F. de Athayde-Filho ${ }^{a, b}$ \\ ${ }^{a}$ Departamento de Química, Universidade Federal da Paraíba, 58059-900 João Pessoa-PB, Brazil \\ ${ }^{b}$ Laboratório de Tecnologia Farmacêutica, Universidade Federal da Paraíba, CP 5009, \\ 58051-970 João Pessoa-PB, Brazil \\ ${ }^{c}$ Departamento de Química Fundamental, Universidade Federal de Pernambuco, \\ 50670-901 Recife-PE, Brazil \\ ${ }^{d}$ Departamento de Química, Universidade Federal de Santa Maria, \\ 97105-900 Santa Maria-RS, Brazil
}

\begin{abstract}
Cálculos semi-empíricos do tipo AM1-TDHF para a primeira hiperpolarizabilidade estática, $\beta(0)$, de dezesseis compostos mesoiônicos do sistema 1,3-tiazólio-5-tiolato foram realizados. Com base nos resultados obtidos, dois novos compostos mesoiônicos, 2-(4-nitrofenil)-3-metil-4(metilfenil)-1,3-tiazólio-5-tiolato e 2-(4-nitrofenil)-3-metil-4-(metoxifenil)-1,3-tiazólio-5-tiolato, foram sintetizados e caracterizados por métodos espectroscópicos e analíticos.

Semiempirical AM1-TDHF calculations of the static first hyperpolarizabilities, $\beta(0)$, of 1,3-thiazolium-5-thiolate mesoionic derivatives were performed. Guided by these results, two new mesoionic compounds - 2-(4-nitrophenyl)-3-methyl-4-(methylphenyl)-1,3-thiazolium-5-thiolate and 2-(4-nitrophenyl)-3-methyl-4-(methoxyphenyl)-1,3-thiazolium-5-thiolate - were synthesized and characterized by analytical and spectroscopic means.
\end{abstract}

Keywords: mesoionic compounds, 1,3-thiazolium-5-thiolate, nonlinear optical properties, semiempirical calculations, photonic devices

\section{Introduction}

During the last few years mesoionic compounds (MIC) have attracted the attention of chemists because of the bonding aspects associated with their unusual structure which can be understood as mesomeric heterocyclic betaines, strongly stabilized by $\pi$-electron delocalization and with large dipole moments. ${ }^{1}$ Such structures can be regarded as equivalents of push-pull organic compounds of the type electron-acceptor (A) - polyenic bridge - electrondonor (D) commonly employed in nonlinear optics. ${ }^{2}$ But, unlike these symmetric polyenic bridges, the mesoionic rings act as asymmetric bridges and the relative positions of the donor/acceptor groups linked to the ring are very

\footnotetext{
*e-mail: gbr@quimica.ufpb.br
}

$\dagger$ in memoriam important. ${ }^{3}$ It has been computationally demonstrated that molecules containing mesoionic rings as asymmetric bridges have a performance for second order nonlinear optical effects equivalent to symmetric polyenic bridges containing more than seven conjugated double bonds. ${ }^{2}$

In a previous article ${ }^{3}$ we showed that, by employing the Time-Dependent Hartree-Fock (TDHF) method with the semiempirical AM1 Hamiltonian, ${ }^{4}$ one can obtain values for the first static hyperpolarizability, $\beta(0)$, that correlate well with the experimentally observed values for this property. And we have also described, the synthesis and experimental measurements of the nonlinear absorption of 1,3-thiazolium5-thiolate mesoionic compounds (Figure 1) using nanosecond laser pulses with wavelengths of 570,605 and $618 \mathrm{~nm}$; led to the observation of nonlinear absorption cross-sections $\sigma_{2}$ as large as $10^{-45} \mathrm{~cm}^{4} \mathrm{~s}$ per photon. ${ }^{5}$ These compounds are seemingly very promising for photonic applications. Guided by our 
AM1-TDHF calculations, we have been further designing and synthesizing mesoionic compounds in our laboratories for photonic applications. ${ }^{6,7}$

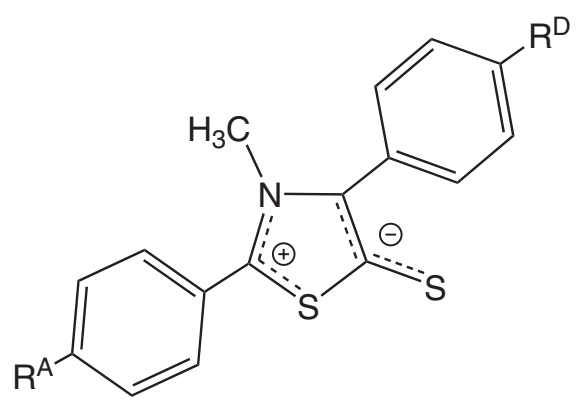

Figure 1. Structure of 1,3-thiazolium-5-thiolate mesoionic compounds.

Accordingly, we synthesized new examples of 1,3-thiazolium-5-thiolate mesoionic compounds, especially those with large AM1-TDHF calculated values for $\beta(0)$.

Figure 1 shows that the mesoionic ring possesses two charged regions separated by what are essentially single bonds. ${ }^{8}$ It is this charge separation (asymmetry) that is responsible for the large values of $\beta(0)$ obtained for this class of compounds. Recently, it was proposed by Kuzyk and co-workers ${ }^{9,10}$ that conjugated bridges with sites of reduced conjugation may be excellent prototypes for increasing the values of $\beta(0)$. It is worthwhile to mention that the mesoionic compounds that we have been studying for nonlinear optics applications since $1996,{ }^{3}$ can be considered as an early example of this paradigm.

Figure 1 shows two groups, $\mathrm{R}^{\mathrm{A}}$ and $\mathrm{R}^{\mathrm{D}}$, linked to the para positions of two phenyl groups. The group containing $\mathrm{R}^{\mathrm{D}}$ is bound to the anionic region of the mesoionic ring and the group containing $\mathrm{R}^{\mathrm{A}}$ is bound to the cationic region. In order to enhance the donating properties of the anionic region of the mesoionic ring, we are studying compounds where $\mathrm{R}^{\mathrm{D}}$ is an electron-donor group. Similarly, we are using electron-acceptor groups in $\mathrm{R}^{\mathrm{A}}$ in order to enhance the accepting properties of the cationic region of the ring. ${ }^{3}$

\section{Theoretical details}

Initially, consider the semiempirical AM1-TDHF calculations of $\beta(0)$ for a set of sixteen mesoionic molecules (MIC-1 to MIC-16) containing the 1,3-thiazolium-5thiolate ring (Figure 1).

The ground state geometries of the molecules were optimized using the AM1 semiempirical method implemented in MOPAC module of the Scigress Explorer 7.7 package. ${ }^{11}$ The MOPAC keywords used during geometry optimization were: GNORM=0.01 (to guarantee an energy minimum), SCFCRT=1.D-8 (to increase the
SCF convergence criteria) and XYZ (to describe the optimized geometry in Cartesian coordinates). The nonlinear optical properties were calculated analytically using the TDHF methodology, implemented in the MOPAC module, using the following keywords to predict first static hyperpolarizability: $\operatorname{POLAR}(\mathrm{E}=(0.0), \mathrm{BETA}=1, \mathrm{IWFLB}=0$, TOL=1.D-9, BTOL=1.D-9). We used $\mathrm{E}=(0.0)$ to specify the energy of the incident radiation as zero electron volts, $\mathrm{BETA}=1$ and IWFLB $=0$ for the iterative calculation of the first static hyperpolarizability, TOL and BTOL are, respectively, the cutoff tolerance for the calculation of the polarizability and first hyperpolarizability. The calculated $\beta(0)$ values are given in Table 1.

Table 1. AM1-TDHF first static hyperpolarizabilities, $\beta(0)$, and experimental nonlinear absorption cross-sections, $\sigma_{2}$, for MIC-1 to MIC-16

\begin{tabular}{lcccc}
\hline MIC & $\mathrm{R}^{\mathrm{A}}$ & $\mathrm{R}^{\mathrm{D}}$ & $\begin{array}{c}\beta(0) / \\
\left(10^{-30} \mathrm{esu}\right)\end{array}$ & $\begin{array}{c}\sigma_{2} /\left(10^{-45} \mathrm{~cm}^{4} \mathrm{~s}\right. \\
\text { per }\end{array}$ photon $)^{\mathrm{a}}$ \\
\hline MIC-1 & $\mathrm{H}$ & $\mathrm{H}$ & 23.16 & - \\
MIC-2 & $\mathrm{H}$ & $\mathrm{CH}_{3}$ & 25.90 & - \\
MIC-3 & $\mathrm{H}$ & $i$-Pr & 25.17 & - \\
MIC-4 & $\mathrm{H}$ & $\mathrm{OCH}_{3}$ & 28.44 & - \\
MIC-5 & $\mathrm{Cl}$ & $\mathrm{H}$ & 24.81 & - \\
MIC-6 & $\mathrm{Cl}$ & $\mathrm{CH}_{3}$ & 27.73 & 18 \\
MIC-7 & $\mathrm{Cl}$ & $i$-Pr & 28.08 & - \\
MIC-8 & $\mathrm{Cl}$ & $\mathrm{OCH}_{3}$ & 30.82 & - \\
MIC-9 & $\mathrm{CF}_{3}$ & $\mathrm{H}_{3}$ & 34.25 & - \\
MIC-10 & $\mathrm{CF}_{3}$ & $\mathrm{CH}_{3}$ & 38.11 & 30 \\
MIC-11 & $\mathrm{CF}_{3}$ & $i$-Pr & 38.89 & 49 \\
MIC-12 & $\mathrm{CF}_{3}$ & $\mathrm{OCH}_{3}$ & 41.69 & - \\
MIC-13 & $\mathrm{NO}_{2}$ & $\mathrm{H}$ & 51.59 & - \\
MIC-14 & $\mathrm{NO}_{2}$ & $\mathrm{CH}_{3}$ & 56.06 & - \\
MIC-15 & $\mathrm{NO}_{2}$ & $i$-Pr & 57.22 & 345 \\
MIC-16 & $\mathrm{NO}_{2}$ & $\mathrm{OCH}_{3}$ & 61.49 & - \\
\hline
\end{tabular}

${ }^{\mathrm{a}}$ values from reference 5 .

\section{Results and Discussion}

The dependence of $\beta(0)$ on the electronic character of the aromatic substituents directly attached to the mesoionic ring is given in Figure 2. The left part of Figure 2 gives $\beta(0)$ as a function of the Hammett $\sigma_{p}$ electronic parameters of the $\mathrm{R}^{\mathrm{D}}$ groups on the aromatic substituents $\left(p-\mathrm{C}_{6} \mathrm{H}_{4} \mathrm{R}^{\mathrm{D}}, \mathrm{R}^{\mathrm{D}}=\mathrm{H}\right.$, $\mathrm{Me}, i-\mathrm{Pr}, \mathrm{OMe}$ ) attached to carbon four of the mesoionic ring: ${ }^{12}$ the graph clearly shows that the larger the electron donating ability of the $\mathrm{R}^{\mathrm{D}}$ group, the larger is the first static hyperpolarizabily $\beta(0)$ with an almost linear trend for each $p-\mathrm{C}_{6} \mathrm{H}_{4} \mathrm{R}^{\mathrm{A}}$ group attached to carbon two of the mesoionic ring. Correlation of $\beta(0)$ with the positive $\sigma_{p}$ parameter of 
$\mathrm{R}^{\mathrm{A}}$ (right) shows that, the larger the electron withdrawing ability of $\mathrm{R}^{\mathrm{A}}$ is, the larger is $\beta(0)$, but, this time, the increase follows a quadratic function.

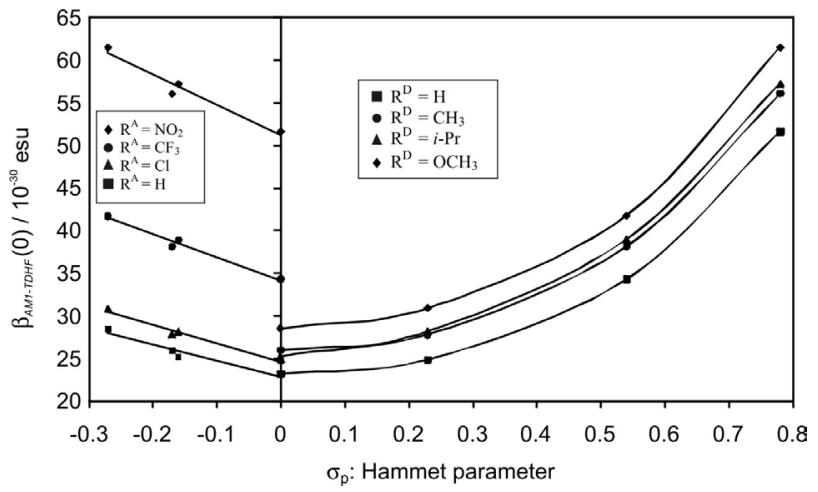

Figure 2. Dependence of the AM1-TDHF $\beta(0)$ magnitude on the electronic character of the aromatic substituents attached to the mesoionic ring $\left(\mathrm{R}^{\mathrm{A}}\right.$ and $\mathrm{R}^{\mathrm{D}}$ groups).

Figure 2 shows that the calculated hyperpolarizabilities are much more susceptible to substitutions in $\mathrm{R}^{\mathrm{A}}$ than to substitutions in $\mathrm{R}^{\mathrm{D}}$, i.e., varying the group $\mathrm{R}^{\mathrm{A}}$ for a fixed $\mathrm{R}^{\mathrm{D}}$ results in much larger variations in the calculated hyperpolarizabilities than when we vary $\mathrm{R}^{\mathrm{D}}$ for a fixed $\mathrm{R}^{\mathrm{A}}$. This result is not unexpected considering that the exocyclic group of the mesoionic ring already acts as a strong electron-donor group, while the cationic region of the ring does not have a well defined electron-accepting atom and needs a group in $\mathrm{R}^{\mathrm{A}}$ to direct the electron-accepting properties of the region.

Mesoionic compounds are conveniently described by a two molecular orbital (MO) model $^{3}$; one MO is associated with the delocalized negative $\pi$-charge (HOMO) and linked to the $\mathrm{C}_{6} \mathrm{H}_{4} \mathrm{R}^{\mathrm{D}}$ group and the second $\mathrm{MO}$ is associated with the delocalized positive $\pi$-charge (LUMO) linked to the $\mathrm{C}_{6} \mathrm{H}_{4} \mathrm{R}^{\mathrm{A}}$ aryl group. An electron-withdrawing group attached to the LUMO (cationic region) decreases the energy of this MO, while the electron-donating group of

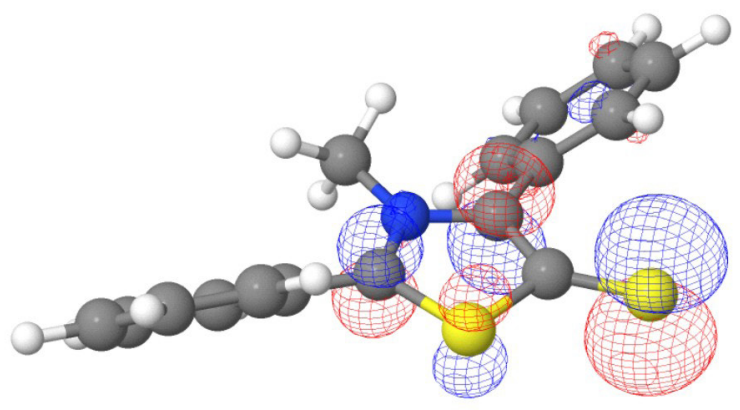

HOMO

(a) the $\mathrm{C}_{6} \mathrm{H}_{4} \mathrm{R}^{\mathrm{D}}$ group tends to destabilize the HOMO (anionic region).

In Figure 3 we have a drawing of the HOMO and LUMO of a representative molecule (MIC-1). We can clearly see that these orbitals are asymmetrically localized in the molecule. The most important electronic excitation in mesoionic compounds is a charge transfer transition from the HOMO to the LUMO involving a large dipole moment change. ${ }^{3}$ Both the decrease of the excitation energy and the increase of the magnitude of dipole moment change upon excitation determine the magnitude of $\beta(0)$, which in turn determines the nonlinear optical properties of the compound.

In Table 1 we also have some experimental values for the nonlinear absorption cross-sections $\sigma_{2}$ of some of the molecules, measured using nanosecond laser pulses with a wavelength of $570 \mathrm{~nm} .{ }^{5}$ We can see that, as the calculated values of $\beta(0)$ increase, the experimentally observed values of $\sigma_{2}$ also increase and that the best $\sigma_{2}$ value $\left(345 \times 10^{-45} \mathrm{~cm}^{4} \mathrm{~s}\right.$ per photon) was produced for the 2-(4-nitrophenyl)-3-methyl4-(4-isopropylphenyl)-1,3-thiazolium-5-thiolate (MIC-15, $\left.\beta(0)=57.22 \times 10^{-30} \mathrm{esu}\right)$.

Our calculations indicate that 2-(4-nitrophenyl)-3methyl-4-(methoxyphenyl)-1,3-thiazolium-5-thiolate (MIC-16) has an even larger first static hyperpolarizability $\left(\beta(0)\right.$ of $\left.61.49 \times 10^{-30} \mathrm{esu}\right)$ than MIC-15. Therefore, aiming at producing this improved material for photonic applications, we set up to establish a synthetic protocol leading to it; and, through this route, we also synthesized MIC-14 [2-(4-nitrophenyl)-3-methyl-4-(methylphenyl)1,3-thiazolium-5-thiolate] which displayed an appreciable $\beta(0)$ value.

The synthetic route leading to these new mesoionics was essentially the same used previously and involves the in situ 1,3-dipolar cycloaddition/cycloreversion with $\mathrm{CS}_{2}$ of the corresponding 1,3-oxazolinium-5-olates prepared by $\mathrm{N}$-aroylation of $\mathrm{C}$-aryl-methylglicines (Figure 4). ${ }^{13}$

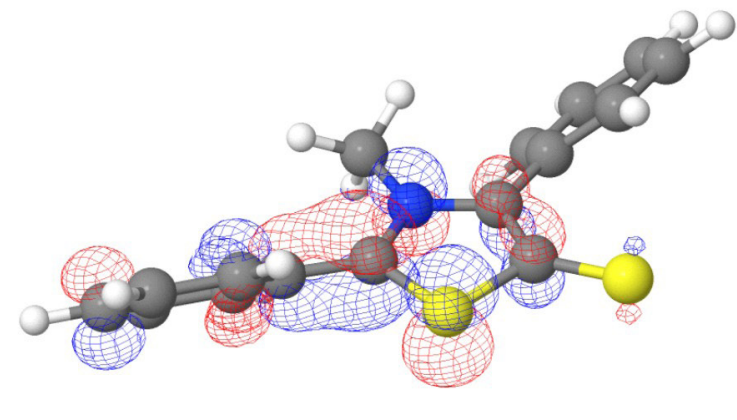

LUMO

(b)

Figure 3. Drawing of the (a) HOMO and (b) LUMO of a representative molecule (MIC-1) where we can see the asymmetry of these orbitals. 

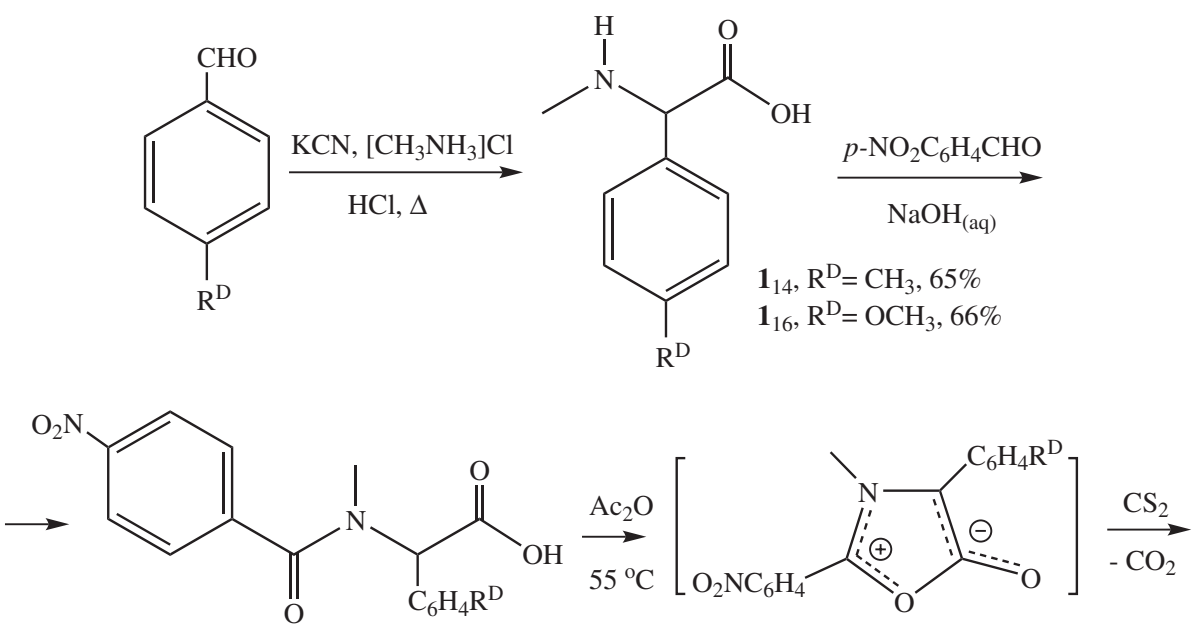

$\mathbf{2}_{14}, \mathrm{R}^{\mathrm{D}}=\mathrm{CH}_{3}, 52 \%$

$\mathbf{2}_{16}, \mathrm{R}^{\mathrm{D}}=\mathrm{OCH}_{3}, 45 \%$

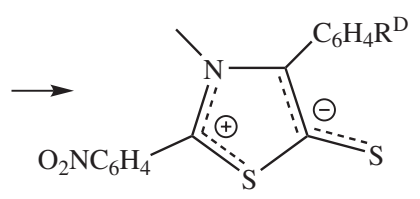

MIC-14, $\mathrm{R}^{\mathrm{D}}=\mathrm{CH}_{3}, 37 \%$

MIC-16, $\mathrm{R}^{\mathrm{D}}=\mathrm{OCH}_{3}, 56 \%$

Figure 4. Preparation of 1,3-thiazolium-5-thiolate mesoionics.

Compounds MIC-14 and MIC-16 are air stable solids, which had their molecular formulae established by elemental microanalysis and confirmed by mass spectrometry. Other spectroscopic data $\left({ }^{1} \mathrm{H},{ }^{13} \mathrm{C}\right.$ NMR and infra red) are in complete agreement with the proposed structures. All these details are in the Experimental section.

Studies of ${ }^{1} \mathrm{H}$ NMR of mesoionic compounds are not very informative when there are not any hydrogen in the heterocyclic ring, however are important in the detection of hydrogens in the substituent groups. In contrast, the ${ }^{13} \mathrm{C}$ NMR spectroscopy is an important tool to characterize the structure of mesoionic compounds due to the large difference in electronic densities between the two regions of the betainic ring (HOMO and LUMO). This difference in electronic density manifests itself in shielding or deshielding effects of the carbons of the heterocyclic ring and of the carbons of aromatic or aliphatic groups linked to the mesoionic ring. The three peaks at ca 160,150, and $140 \mathrm{ppm}$ are attributed to $\mathrm{C} 5, \mathrm{C} 2$, and $\mathrm{C} 4$ respectively (see Figures 5a and 5b). The reason that $\mathrm{C} 4$ is at high field compared with $\mathrm{C} 5$; although both are in the negative region of the mesoionic ring can be related to the significant partial double bond character of the carbon-thiolate bond (C5-S5). The methylic carbon linked to N3 is characterized by a peak at $40 \mathrm{ppm}$ and the methylic protons have chemical shifts around the $3.60 \mathrm{ppm}$, there is a down-field shift as a result of the positive charge on N3. The carbon atoms with chemical shift at low field, 148 and $160.4 \mathrm{ppm}$, are affected by deshielding effects caused, respectively, by the existence of the nitro and methoxy groups.

The ${ }^{13} \mathrm{C}$ NMR (APT, $50 \mathrm{MHz}$, DMSO-d6) study of the compound MIC-14 showed thirteen chemical shifts. Of these, seven were assigned to the quaternary carbons, two to the primary aliphatic carbons and four to the aromatic tertiary carbons. The carbons of the mesoionic ring of MIC-14 have chemical shifts in 152.1; 141.4 and 161.9 ppm assigned, respectively, to C2, C4 e C5 (see Figure 5a). The carbons $\mathrm{C} 10$ and $\mathrm{C} 15$ have chemical shifts of 40.6 and $21.4 \mathrm{ppm}$, while the aromatic carbons have chemical shifts of 132.7 (C6); 129.4 (C7, 7'); 123.8 (C8, 8'); 148.5(C9); 129.6 (C11); 129.8 (C12, 12'); 128.2 (C13, 13') and 139.1 (C14).

The ${ }^{1} \mathrm{H}$ NMR (200 MHz, DMSO-d6) spectrum of MIC-14 shows six hydrogen signals. Of these, two intense singlets were observed in the aliphatic region with an integral of $6 \mathrm{H}$ for the hydrogens $\mathrm{H} 10$ and $\mathrm{H} 15$ of the methyl groups, respectively in 3.64 and $2.38 \mathrm{ppm}$. There was also a signal between 8.27 and 7.23 assigned to the eight aromatic hydrogens.

For compound MIC-16 we observed a similar chemical behavior. The ${ }^{13} \mathrm{C}$ NMR (APT, $50 \mathrm{MHz}$, DMSO-d6) spectrum showed thirteen signals. The carbons of the mesoionic ring showed chemical shifts of $148.7 ; 142.5$ and 162.5 for $\mathrm{C} 2, \mathrm{C} 4$ and $\mathrm{C} 5$, respectively (see Figure $5 \mathrm{~b}$ ). Carbons $\mathrm{C} 10$ and $\mathrm{C} 15$ show values of chemical shifts 


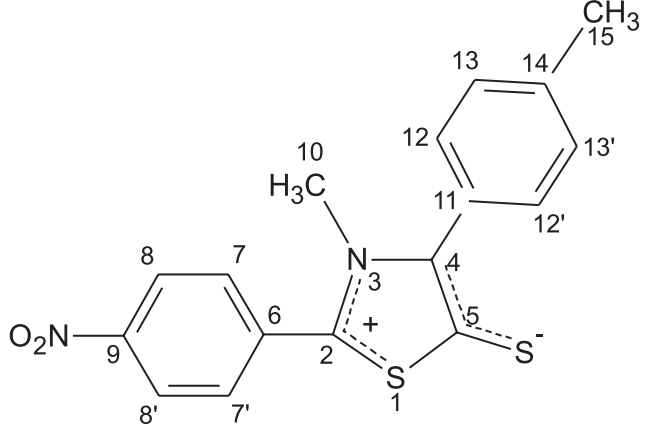

MIC-14

(a)

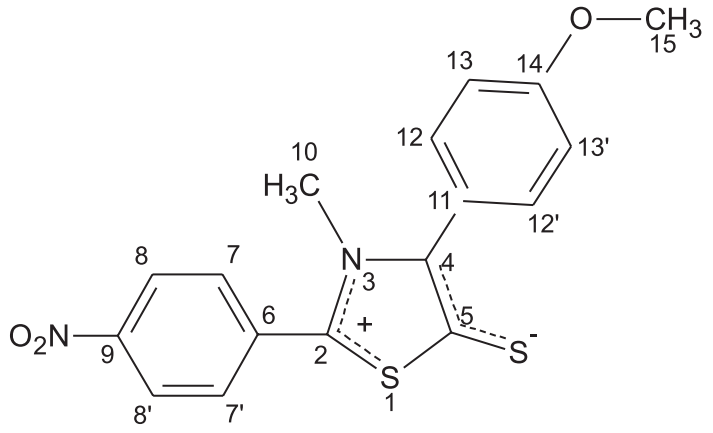

MIC-16

(b)

Figure 5. Schematic representation of the compounds synthesized in the present report. The numbers are employed in the assignment of the peaks of the ${ }^{1} \mathrm{H}$ and ${ }^{13} \mathrm{C}$ NMR spectra. (a) MIC-14 and (b) MIC-16.

that are compatible with the $N$-methyl group in 40.8 and the methoxy group in 55.2. The aromatic carbons have chemical shifts of 132.6 (C6); 130.4 (C7, 7'); 124.6 (C8, 8'); 148.5 (C9); 121.3 (C11); 132.6 (C12, 12'); 114.3 (C13, $\left.13^{\prime}\right)$ and 160.4 (C14).

The ${ }^{1} \mathrm{H}$ NMR (200 MHz, DMSO-d6) spectrum of MIC-16 has six hydrogen signals. Of these, two intense singlets were observed in the aliphatic region with an integral of six hydrogens, three hydrogens were assigned to the $N$-methyl group of the heterocyclic ring in $3.69 \mathrm{ppm}$ and three were assigned to the methoxy group in $3.90 \mathrm{ppm}$. In the region between 8.34 and $7.07 \mathrm{ppm}$ we observed corresponding signals the eight aromatic hydrogens.

The results above are in agreement with the results observed by Athayde-Filho et al. ${ }^{14}$

\section{Conclusions}

In this short report we performed theoretical calculations of the static first hyperpolarizability of sixteen mesoionic compounds of the 1,3-thiazolium-5-thiolate system. Based on our calculations, we synthesized and characterized two novel mesoionic compounds that showed large values for this property. Our next step will be the experimental measurement of the nonlinear optical properties of the two synthesized compounds in order to test our theoretical predictions.

\section{Experimental}

All reagents and solvents were obtained from commercial sources and used as supplied. Mass spectra were obtained on a Finnigan GCQ Mat type quadrupole-ion trap spectrometer. IR spectra $(\mathrm{KBr})$ were obtained on a Bruker IFS66 spectrometer. ${ }^{1} \mathrm{H}$ and ${ }^{13} \mathrm{C}$ NMR spectra (DMSO- $\mathrm{d}_{6}$ with internal TMS) were recorded on a Varian Unity Plus 300 $\mathrm{MHz}$ spectrometer. Elemental Analysis was carried out on a Perkin Elmer Elemental Microanalyser. Melting points were determined on a Kofler hot-plate apparatus combined with a Carl-Zeiss microscope and are uncorrected.

Preparation of $\mathrm{N}$-methyl-C-arylglycines - general procedure

$\mathrm{KCN}(12.50 \mathrm{~g}, 250 \mathrm{mmol})$ and methylammonium chloride were dissolved in distilled $\mathrm{H}_{2} \mathrm{O}(100 \mathrm{~mL})$. An equimolar amount of the aromatic aldehyde dissolved in $\mathrm{MeOH}(100 \mathrm{~mL})$ was added, in portions, with vigorous stirring. The mixture was kept under stirring for $2 \mathrm{~h} . \mathrm{H}_{2} \mathrm{O}$ $(250 \mathrm{~mL})$ was added, followed by addition of toluene $(250 \mathrm{~mL})$. The toluene phase was separated and extracted with $\mathrm{HCl}_{\text {(aq) }} 6 \mathrm{~mol} \mathrm{~L}^{-1}(3 \times 100 \mathrm{~mL})$. The combined acid extract was refluxed for $8 \mathrm{~h}$ giving the products as white crystals formed on cooling. These were filtered off, washed with $\mathrm{CHCl}_{3}$ and dried under the air.

\section{$N$-Methyl-C-(4-methylphenyl)-glycine (1 $\left.{ }_{14}\right)$}

$28.30 \mathrm{~g}(0.16 \mathrm{~mol}), \mathrm{IR}(\mathrm{KBr}) \mathrm{v}_{\max } / \mathrm{cm}^{-1}: 3250,2510,3032$, 2955, 2795, 2722, 1737; ${ }^{1} \mathrm{H}$ NMR (300 MHz, DMSO-d $)$ : $\delta 2.27$ (s, 3H), 2.37 (s, 3H), $4.96(\mathrm{~s}, 1 \mathrm{H}), 7.24(\mathrm{~d}, J 8.1 \mathrm{~Hz}$, $2 \mathrm{H}), 7.36(\mathrm{~d}, J 8.1 \mathrm{~Hz}, 2 \mathrm{H}), 9.64(\mathrm{~s}, 2 \mathrm{H}) ;{ }^{13} \mathrm{C} \mathrm{NMR}(75 \mathrm{MHz}$, DMSO-d ) $_{6} \delta 169.5,139.9,130.1,129.0,128.2,63.1,31.0$, 21.1; MS (EI, 70eV): $\mathrm{m} / \mathrm{z}(\%)=135$ (10.16), $134(100)$, 120 (4.94), 119 (1.66), 91 (14.83), 77 (2.73), 51 (3.30), 42 (34.69); Anal. Calc. (\%) for $\mathrm{C}_{10} \mathrm{H}_{14} \mathrm{ClNO}_{2}=\mathrm{C}, 55.69 ; \mathrm{H}$, 6.54 ; N, 6.49. Found: C, 56.07; H, 6.85; N 6.27; yield 65\%; mp 214-216 ${ }^{\circ} \mathrm{C}$ (recryst. EtOH: $\mathrm{H}_{2} \mathrm{O}(1: 1, \mathrm{v} / \mathrm{v})$ ).

N-Methyl-C-(4-methoxyphenyl)-glycine, $\left(\mathbf{1}_{16}\right)$ $32.00 \mathrm{~g},(0.16 \mathrm{~mol}), \mathrm{IR}(\mathrm{KBr}) v_{\max } / \mathrm{cm}^{-1}: 3188,2501$, 
3006, 2960, 2839, 2776, 2782, 1735; ${ }^{1} \mathrm{H}$ NMR $(300 \mathrm{MHz}$, DMSO-d $\left.\mathrm{d}_{6}\right): \delta 2.35$ (s, 3H), $3.75(\mathrm{~s}, 3 \mathrm{H}), 4.98(\mathrm{~s}, 1 \mathrm{H}), 7.01$ (d, $J 8.8 \mathrm{~Hz}, 2 \mathrm{H}), 7.43$ (d, $J 8.8 \mathrm{~Hz}, 2 \mathrm{H}), 9.81(\mathrm{~s}, 2 \mathrm{H})$; ${ }^{13} \mathrm{C}$ NMR $(75 \mathrm{MHz}$, DMSO-d 6 ) $\delta 169.4,160.2,130.5$, 122.9. 114.6, 62.4. 55.5, 30.5; MS (EI, 70eV): $\mathrm{m} / \mathrm{z}(\%)=$ $196[\mathrm{M}-\mathrm{Cl}]^{+}$(11.59), 195 (1.28), 165 (6.43), 150 (100), 135 (2.64), 107 (4.85), 77 (2.79), 51 (1.37), 42 (25.70); Anal. Calc. (\%) for $\mathrm{C}_{10} \mathrm{H}_{14} \mathrm{ClNO}_{3}=\mathrm{C}, 51.84 ; \mathrm{H}, 6.09$; $\mathrm{N}, 6.05$. Found: C, 52.12; H, 5.95; N, 5.93; yield 66\%; mp $257-258{ }^{\circ} \mathrm{C}$ (recryst. EtOH: $\left.\mathrm{H}_{2} \mathrm{O}(1: 1, \mathrm{v} / \mathrm{v})\right)$.

\section{Preparation of $\mathrm{N}$-amidoacids - general procedure}

$\mathrm{N}$-Methyl-C-arylglycines $\left(\mathbf{1}_{\mathbf{1 4 , 1 6}}\right)(0.30 \mathrm{~mol})$ were dissolved in the minimum amount of $\mathrm{NaOH}_{(\text {aq) }}(10 \%)$ with continuous stirring kept for $2 \mathrm{~h}$. Equimolar amounts of 4-nitro-benzoyl chloride were added dropwise and the reaction stirred for $2 \mathrm{~h}$. During this time, the crude product precipitated. The mixture was neutralized with $\mathrm{HCl}_{\text {(aq) }}$ $(10 \%)$. The white crystalline products were filtered, washed with $\mathrm{H}_{2} \mathrm{O}$, air-dried, and used without further purification:

$N$-(4-Nitrobenzoyl)-N-methyl-C-(4-methylphenyl)-glycine, $(2$,

$5.37 \mathrm{~g},(0.16 \mathrm{~mol}), \mathrm{IR}(\mathrm{KBr}) v_{\max } / \mathrm{cm}^{-1}: 3168,3114$, $3082,2985,2859,2861,1702,1632 ;{ }^{1} \mathrm{H}$ NMR $(300 \mathrm{MHz}$, $\left.\mathrm{CDCl}_{3}\right): \delta 2.35$ (s, 3H), $2.69(\mathrm{~s}, 3 \mathrm{H}), 6.38(\mathrm{~s}, 1 \mathrm{H}) .7 .20$ (d, $J$ $8.2 \mathrm{~Hz}, 2 \mathrm{H}), 7.25(\mathrm{~d}, J 8.2 \mathrm{~Hz}, 2 \mathrm{H}), 7.61(\mathrm{~d}, J 8.4 \mathrm{~Hz}, 2 \mathrm{H})$, 8.24 (d, $J 8.4 \mathrm{~Hz}, 2 \mathrm{H}), 7.90$ (s, 1H); ${ }^{13} \mathrm{C}$ NMR $(75 \mathrm{MHz}$, $\left.\mathrm{CDCl}_{3}\right): \delta 173.9,170.6,148.5,141.4,139.1,129.7,129.6$, $129.4,128.1,123.8,60.8,34.6,21,1 ;$ MS (EI, $70 \mathrm{eV}$ ): $\mathrm{m} / \mathrm{z}$ $(\%)=327(1.74), 283\left[\mathrm{M}-\mathrm{CO}_{2} \mathrm{H}\right]^{+}(15.02), 178(100), 150$ (27.48), 133 (13.91), 132 (73.93), 122 (2.19), 117 (2.55), 91 (9.44); Anal. Calc. for $\mathrm{C}_{17} \mathrm{H}_{16} \mathrm{~N}_{2} \mathrm{O}_{5}: \mathrm{C}, 62.19 ; \mathrm{H}, 4,91$; N, 8,53. Found: C, 61.88; H, 4.93; N, 8.67; yield 53\%, mp $169-171{ }^{\circ} \mathrm{C}$.

$N$-(4-Nitrobenzoyl)-N-methyl-C-(4-methoxyphenyl)glycine, $\left(2_{16}\right)$

$4.72 \mathrm{~g},(0.13 \mathrm{~mol}) ; \mathrm{IR}(\mathrm{KBr}) \mathrm{v}_{\max } / \mathrm{cm}^{-1}: 3001,2956$, 2839, 1699, 1631, 1537, 1349; ${ }^{1} \mathrm{H} \mathrm{NMR}\left(300 \mathrm{MHz}, \mathrm{CDCl}_{3}\right)$ : $\delta 2.67(\mathrm{~s}, 3 \mathrm{H}), 3.77(\mathrm{~s}, 3 \mathrm{H}), 6.32(\mathrm{~s}, 1 \mathrm{H}), 6.88(\mathrm{~d}, J 8.3$ $\mathrm{Hz}, 2 \mathrm{H}), 7.24$ (d, J $8.3 \mathrm{~Hz}, 2 \mathrm{H}), 7.58(\mathrm{~d}, J 8.2 \mathrm{~Hz}, 2 \mathrm{H})$, $8.21(\mathrm{~d}, J 8.2 \mathrm{~Hz}, 2 \mathrm{H}), 8.67(\mathrm{~s}, 1 \mathrm{H}) ;{ }^{13} \mathrm{C} \mathrm{NMR}(75 \mathrm{MHz}$, $\left.\mathrm{CDCl}_{3}\right): \delta 173.8,170.6,160.0,148.4,141.3,130.9,128.1$, 124.4, 123.8, 114.4, 60.6, 55.3, 34.6; MS (EI, $70 \mathrm{eV}): \mathrm{m} / \mathrm{z}$ $(\%)=344[\mathrm{M}] \div(1.01), 300(55.6), 299$ (38.35), $194(100)$, 150 (37.31), 149 (70.32), 148 (95.21), 133 (11.36), 122 (9.56), 107 (2.32); Anal. Calc. for $\mathrm{C}_{17} \mathrm{H}_{16} \mathrm{~N}_{2} \mathrm{O}_{6}$ : C, 59.30; H, 4.68; N, 8.14. Found: C, 60.02; H, 4.61; N, 8.03; yield $44.60 \%$, mp $181-183{ }^{\circ} \mathrm{C}$.
Preparation of mesoionics compounds - general procedure

The $N$-aroyl- $N$-methyl- $C$-arylglycine $\left(\mathbf{2}_{14}\right.$ or $\left.\mathbf{2}_{16}\right)$ $(1.4 \mathrm{mmol})$ was dissolved in $\mathrm{Ac}_{2} \mathrm{O}(20 \mathrm{~mL})$ and heated, with stirring, at $55{ }^{\circ} \mathrm{C}$ for $15 \mathrm{~min}$. After cooling to ambient temperature, $\mathrm{CS}_{2}(20 \mathrm{~mL})$ was added and the reaction mixture allowed to stand for $48 \mathrm{~h}$. $\mathrm{MeOH} / \mathrm{H}_{2} \mathrm{O}(1: 1)$ was then added until the mixture became cloudy. After standing for $24 \mathrm{~h}$, the desired products precipitated as orange-red crystals, which were recrystallized from $\mathrm{MeOH}$.

2-(4-Nitrophenyl)-3-methyl-4-(4-methyphenyl)-1,3thiazolium-5-thiolate, (MIC-14)

$0.19 \mathrm{~g},(0.51 \mathrm{mmol}) ; \mathrm{IR}(\mathrm{KBr}) \mathrm{v}_{\max } / \mathrm{cm}^{-1}: 3117,3062$, 2994, 1607, 1542, 1495, 1429, 1351, 1294; ' ${ }^{\mathrm{H}} \mathrm{NMR}(300$ $\mathrm{MHz}, \mathrm{CDCl}_{3}$ ): $\delta 2.38$ (s, 3H), 3.64 (s, 3H), $7.23(\mathrm{~d}, J 8.2 \mathrm{~Hz}$, 2H), 7.28 (d, J 8.2 Hz, 2H), 7.64 (d, J $8.8 \mathrm{~Hz}, 2 \mathrm{H}), 8.27$ (d, $J 8.8 \mathrm{~Hz}, 2 \mathrm{H}) ;{ }^{13} \mathrm{C} \mathrm{NMR}\left(75 \mathrm{MHz}, \mathrm{CDCl}_{3}\right): \delta 161.9,152.1$, 141.4. 139.1, 148.5, 132.7, 129.8, 129.6, 129.4, 128.2, 123.8, 40.6, 21.4; MS (EI, $70 \mathrm{eV}): \mathrm{m} / \mathrm{z}(\%)=343[\mathrm{M}+1](17.74)$, 342 [M!] (100), 327 (8.07), 296 (19.94), 281 (15.43), 179 (20.14), 166 (2.99), 135 (9.43), 119 (4.41), 91 (4.23), 75 (2.08); Anal. Calc. for $\mathrm{C}_{17} \mathrm{H}_{14} \mathrm{~N}_{2} \mathrm{O}_{2} \mathrm{~S}_{2}: \mathrm{C}, 59.63 ; \mathrm{H}, 4.12 ; \mathrm{N}$, 8.18; S, 18.73. Found: C, 60.04; H, 4.71; N, 8.27; S, 19.03; yield $37 \%$, mp $183-185^{\circ} \mathrm{C}$ (recryst. EtOH: $\mathrm{H}_{2} \mathrm{O}(1: 1, \mathrm{v} / \mathrm{v})$ ).

2-(4-Nitrophenyl)-3-methyl-4-(4-metoxyphenyl)-1,3thiazolium-5-thiolate, (MIC-16)

$0.29 \mathrm{~g},(0.78 \mathrm{mmol})$; IR (KBr) $v_{\max } / \mathrm{cm}^{-1}: 3009,2967$, 2897,1590, 1489, 1513, 1426, 1334, 1282; ${ }^{1} \mathrm{H}$ NMR $\left(300 \mathrm{MHz}, \mathrm{CDCl}_{3}\right): \delta 3.90(\mathrm{~s}, 3 \mathrm{H}), 3.69(\mathrm{~s} ; 3 \mathrm{H}), 7.07(\mathrm{~d}$, $J 8.8 \mathrm{~Hz}, 2 \mathrm{H}), 7.48(\mathrm{~d}, J 8.8 \mathrm{~Hz}, 2 \mathrm{H}), 7.88(\mathrm{~d}, J 8.4 \mathrm{~Hz}$, $2 \mathrm{H}), 8.34(\mathrm{~d}, J 8.4 \mathrm{~Hz}, 2 \mathrm{H}) ;{ }^{13} \mathrm{C} \mathrm{NMR}\left(75 \mathrm{MHz}, \mathrm{CDCl}_{3}\right)$ : $\delta 162.5,160.4,148.7,148.5,142.5,132.6,130.4,124.6$, 121.3, 114.3, 55.2, 40.8; MS (EI, $70 \mathrm{eV}): \mathrm{m} / \mathrm{z}(\%)=359$ $[\mathrm{M}+1]^{+}(17), 358[\mathrm{M}] \pm$ (94.62), 343 (9.58), 312 (47.77), 297 (32.37), 282 (11.51), 210 (9.95), 195 (100), 166 (6.64), 163 (18.62), 151 (29.44), 135 (40.27), 63 (17.59); Anal. Calc. for $\mathrm{C}_{17} \mathrm{H}_{14} \mathrm{~N}_{2} \mathrm{O}_{3} \mathrm{~S} 2 \mathrm{C}, 56.96 ; \mathrm{H}, 3.94 ; \mathrm{N}, 7.82 ; \mathrm{S} 17.89$. Found: C, 57.13; H, 3.87; N, 8.03; S, 18.03; 56\%, mp 215$217^{\circ} \mathrm{C}$ (recryst. EtOH: $\left.\mathrm{H}_{2} \mathrm{O}(1: 1, \mathrm{v} / \mathrm{v})\right)$.

\section{Supplementary Information}

Supplementary data are available free of charge at http://jbcs.sbq.org.br, as PDF file.

\section{Acknowledgments}

The authors would like to thank CNPq (Brazil) for research grants and for scholarships. 


\section{References}

1. de Athayde, P. F.; Miller, J.; Simas, A. M.; Synthesis 2000, 11, 1565.

2. Silva, A. M. S.; da Rocha, G. B.; Menezes, P. H.; Miller, J.; Simas, A. M.; J. Braz. Chem. Soc. 2005, 16, 583.

3. Moura, G. L. C.; Simas, A. M.; Miller, J.; Chem. Phys. Lett. 1996, 257, 639.

4. Dewar, M. J. S.; Zoebisch, E. G.; Healy, E. F.; Stewart, J. J. P.; J. Am. Chem. Soc. 1985, 107, 3902.

5. Pilla, V.; de Araújo, C. B.; Lira, B. F.; Simas, A. M.; Miller, J., Athayde-Filho, P.F.; Opt. Commun. 2006, 264, 225.

6. Rakov, N.; de Araújo, C. B.; da Rocha, G. B.; Simas, A. M.; Athayde-Filho, P. A. F.; Miller J.; Chem. Phys. Lett. 2000, 332, 13.

7. Bezerra Jr, A. G.; Gomes, A. S. L.; Athayde-Filho, P. F; da Rocha G. B.; Miller, J.; Simas A. M.; Chem.Phys. Lett. 1999, $309,421$.
8. de Oliveira, M. B.; Miller, J.; Pereira, A. B.; Galembeck, S. E.; de Moura, G. L. C.; Simas, A. M.; Phosphorus, Sulfur Silicon Relat. Elem. 1996, 108, 75.

9. Zhou, J. F.; Kuzyk, M. G.; Watkins, D. S.; Opt. Lett. 2006, 31, 2891.

10. Perez-Moreno, J.; Zhao, Y.; Clays, K.; Kuzyk, M. G.; Opt. Lett. 2007, 32, 59 .

11. Scigress Explorer version 7.7; Fujitsu: Tokyo, Japan, 2008.

12. Hansch, C.; Leo, A.; Taft, R.W.; Chem. Rev. 1991, 91, 165.

13. Lira, B. F.; de Athayde, P. F.; Miller, J.; Simas, A. M.; Dias, A. D.; Vieira, M. J.; Molecules 2002, 7, 791.

14. Athayde-Filho P. F.; Miller J.; Simas A. M.; Lira B. F.; Luis, J. A. S.; Zuckerman-Schpector, J.; Synthesis 2003, 5, 685.

Received: May 15, 2009 Web Release Date: February 4, 2010 


\section{1,3-Thiazolium-5-thiolates Mesoionic Compounds: Semiempirical Evaluation of their First Static Hyperpolarizabilities and Synthesis of New Examples}

Bruno F. Lyra, ${ }^{a, b}$ Soraya A. de Morais, ${ }^{a}$ Gerd B. Rocha, ${ }^{*, a}$ Joseph Miller, ${ }^{b, c, t}$

Gustavo L. C. Moura, ${ }^{c}$ Alfredo M. Simas, ${ }^{c}$ Clovis Peppe ${ }^{d}$ and Petrônio F. de Athayde-Filho ${ }^{a, b}$

${ }^{a}$ Departamento de Química, Universidade Federal da Paraíba, 58059-900 João Pessoa-PB, Brazil

${ }^{b}$ Laboratório de Tecnologia Farmacêutica, Universidade Federal da Paraíba, CP 5009, 58051-970 João Pessoa-PB, Brazil

${ }^{c}$ Departamento de Química Fundamental, Universidade Federal de Pernambuco, 50670-901 Recife-PE, Brazil

${ }^{d}$ Departamento de Química, Universidade Federal de Santa Maria, 97105-900 Santa Maria-RS, Brazil

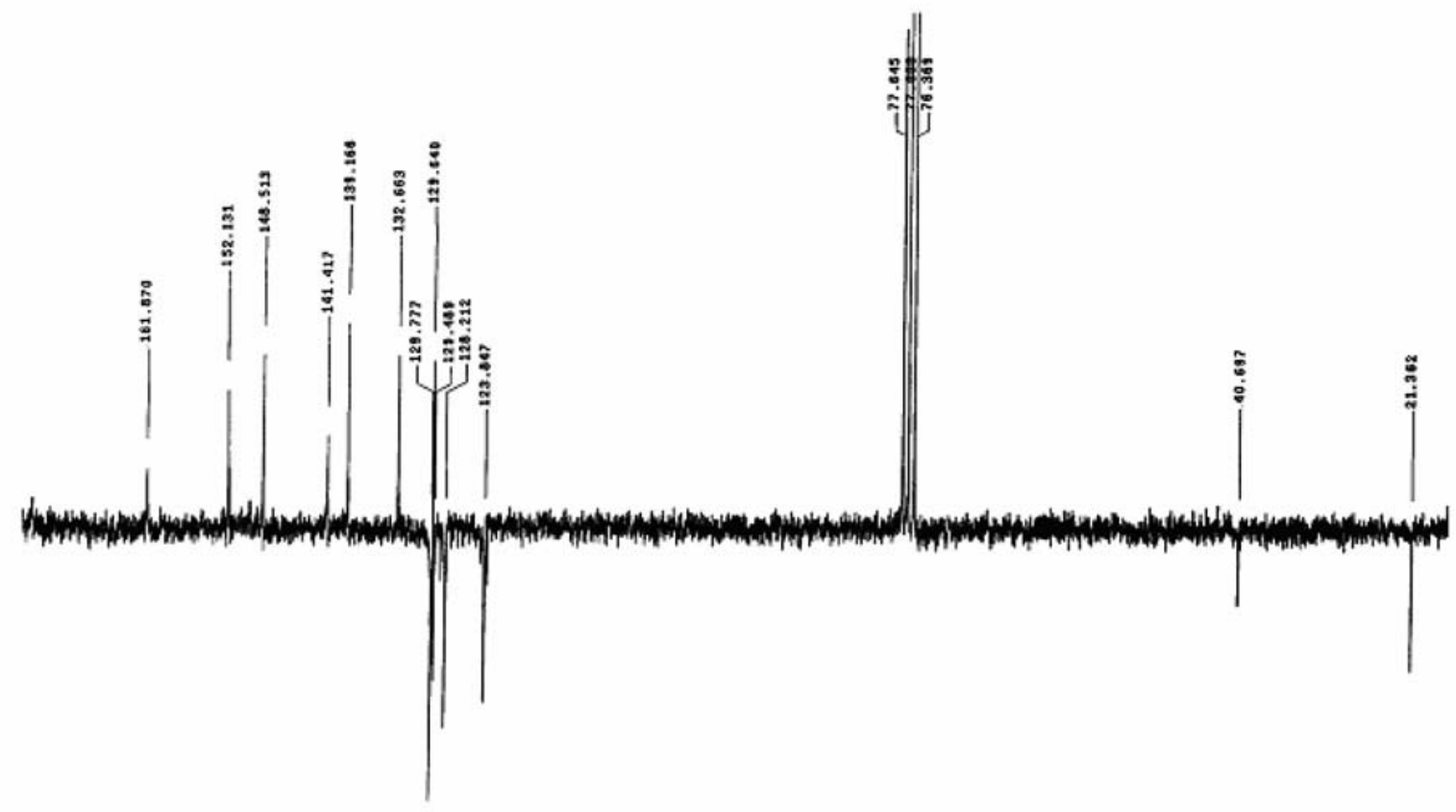

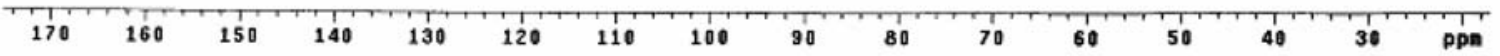

Figure S1. ${ }^{13} \mathrm{C}(\mathrm{APT}) \mathrm{NMR}$ spectrum for MIC-14 $\left(\mathrm{CDCl}_{3}, 50 \mathrm{MHz}\right)$.

*e-mail: gbr@quimica.ufpb.br

$\dagger$ in memoriam 

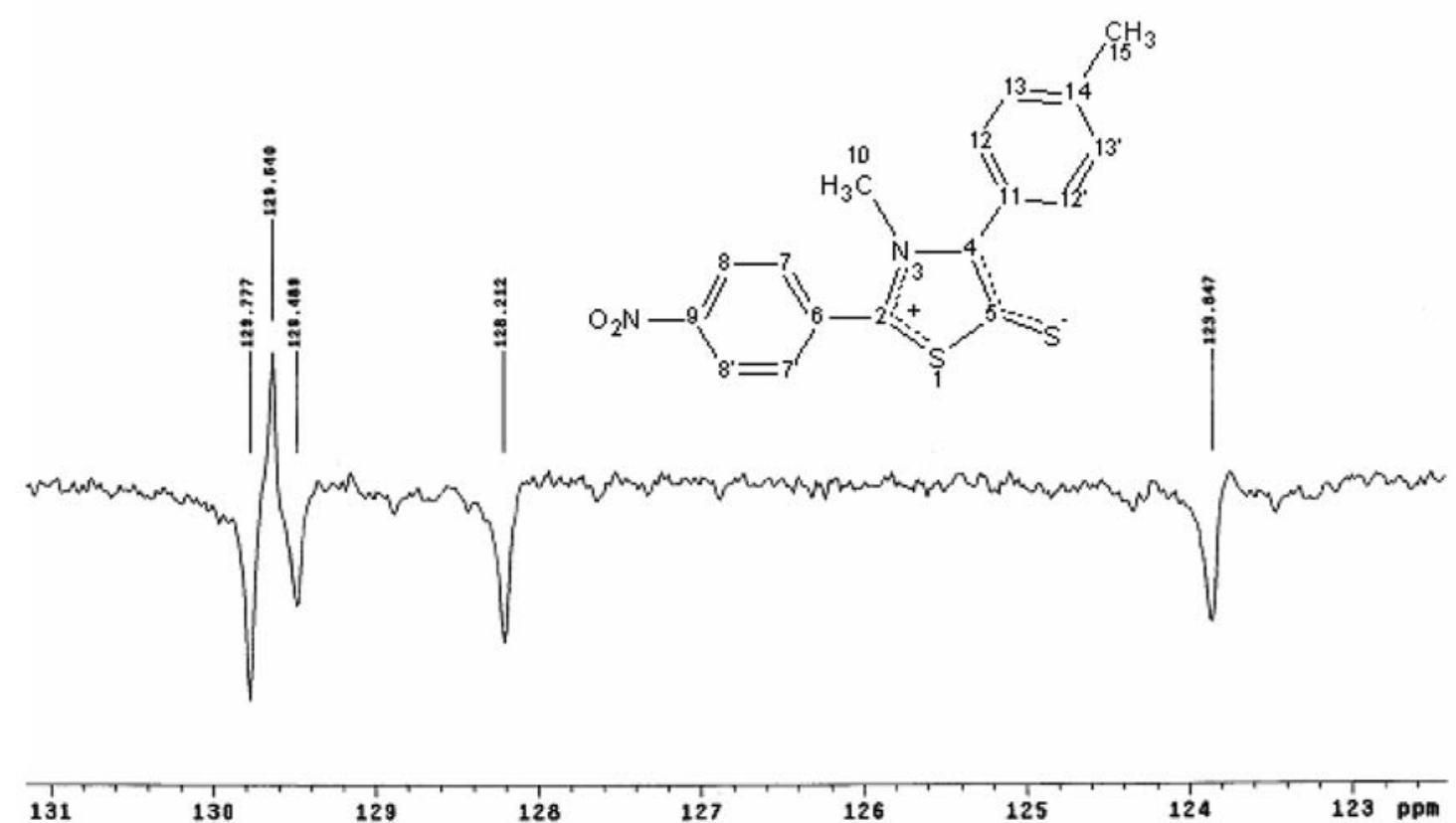

Figure S2. Expanded version of ${ }^{13} \mathrm{C}$ (APT) NMR spectrum for MIC-14 $\left(\mathrm{CDCl}_{3}, 50 \mathrm{MHz}\right)$.

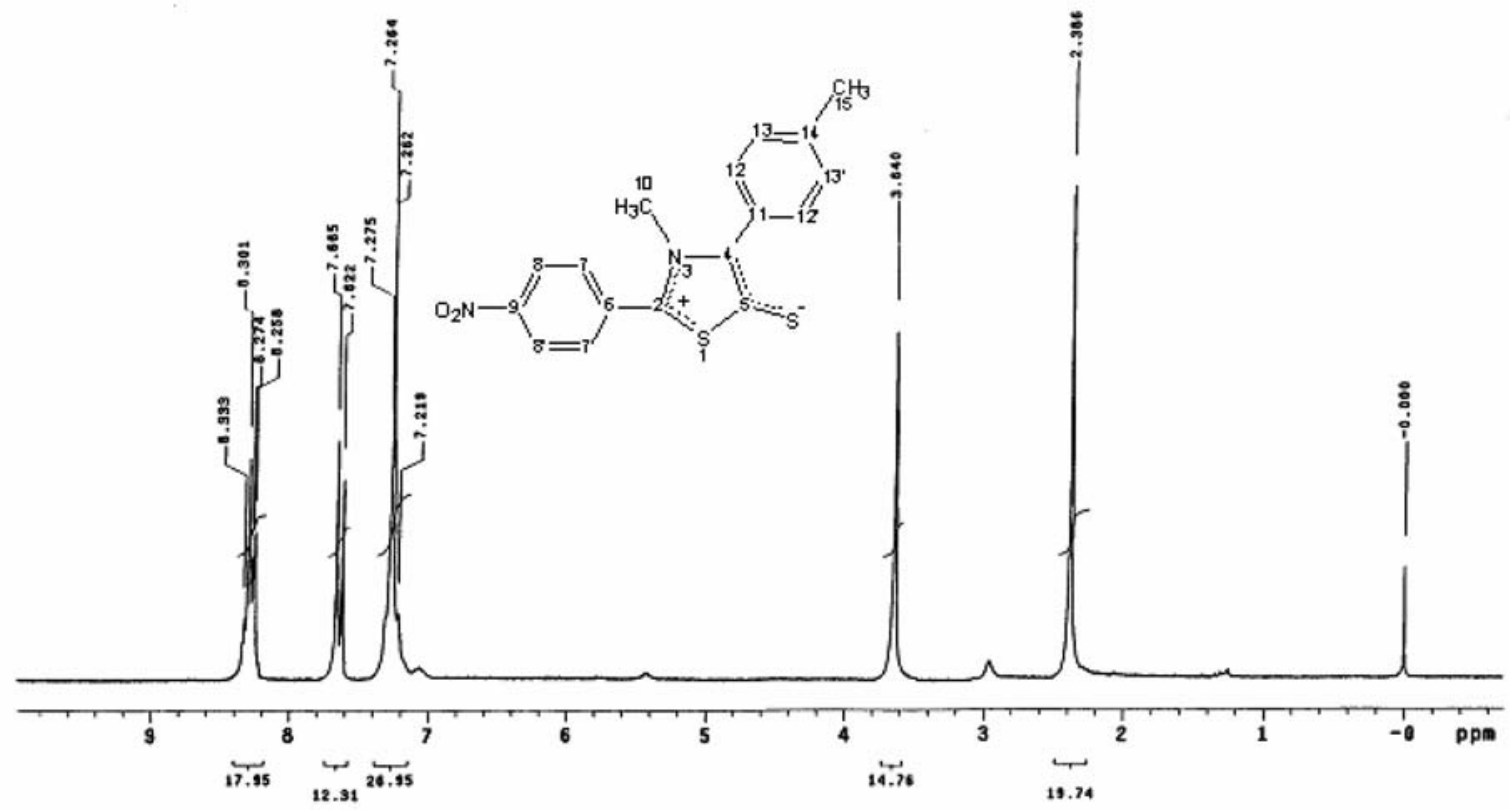

Figure S3. 'H NMR spectrum for MIC-14 ( $\left.\mathrm{CDCl}_{3}, 200 \mathrm{MHz}\right)$. 


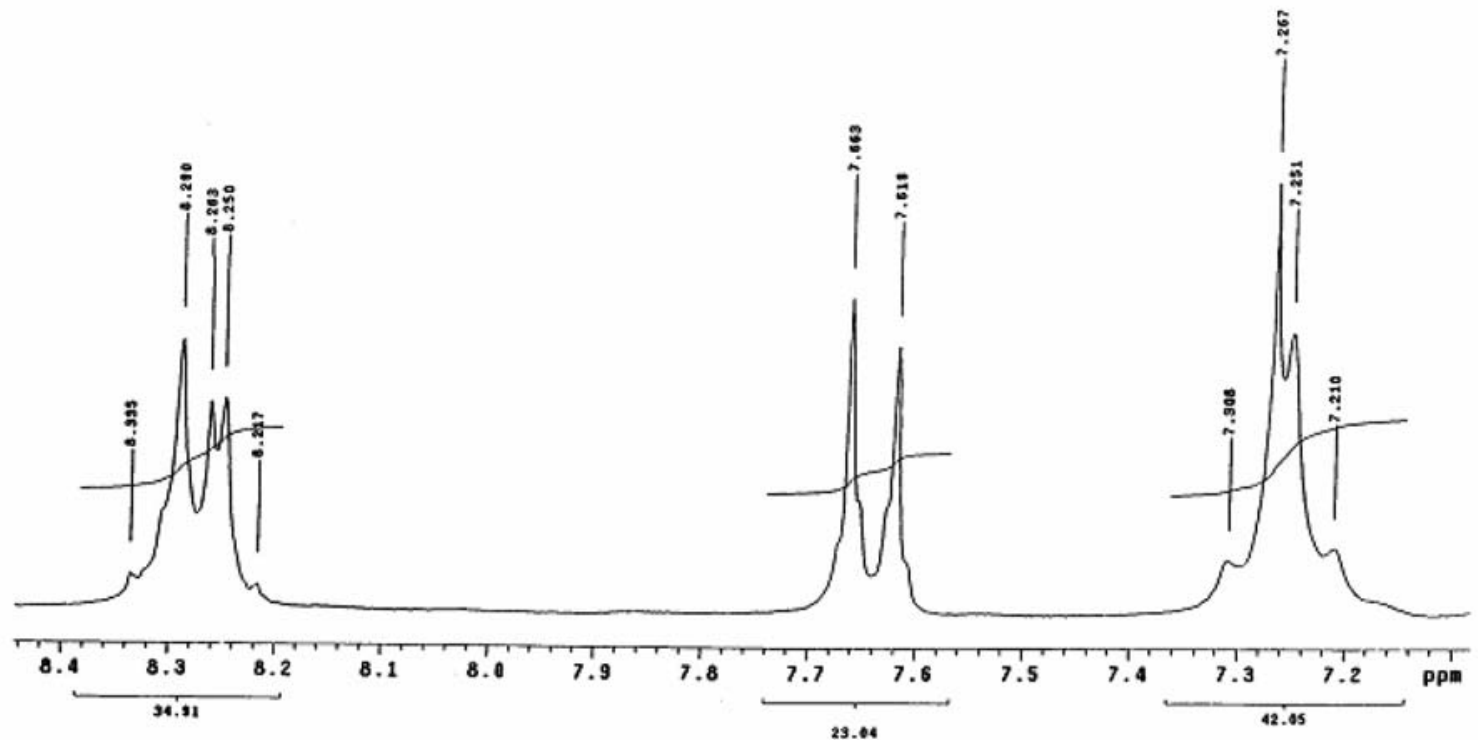

Figure S4. Expanded version of ${ }^{1} \mathrm{H}$ NMR spectrum for $\mathrm{MIC}-14\left(\mathrm{CDCl}_{3}, 200 \mathrm{MHz}\right)$.

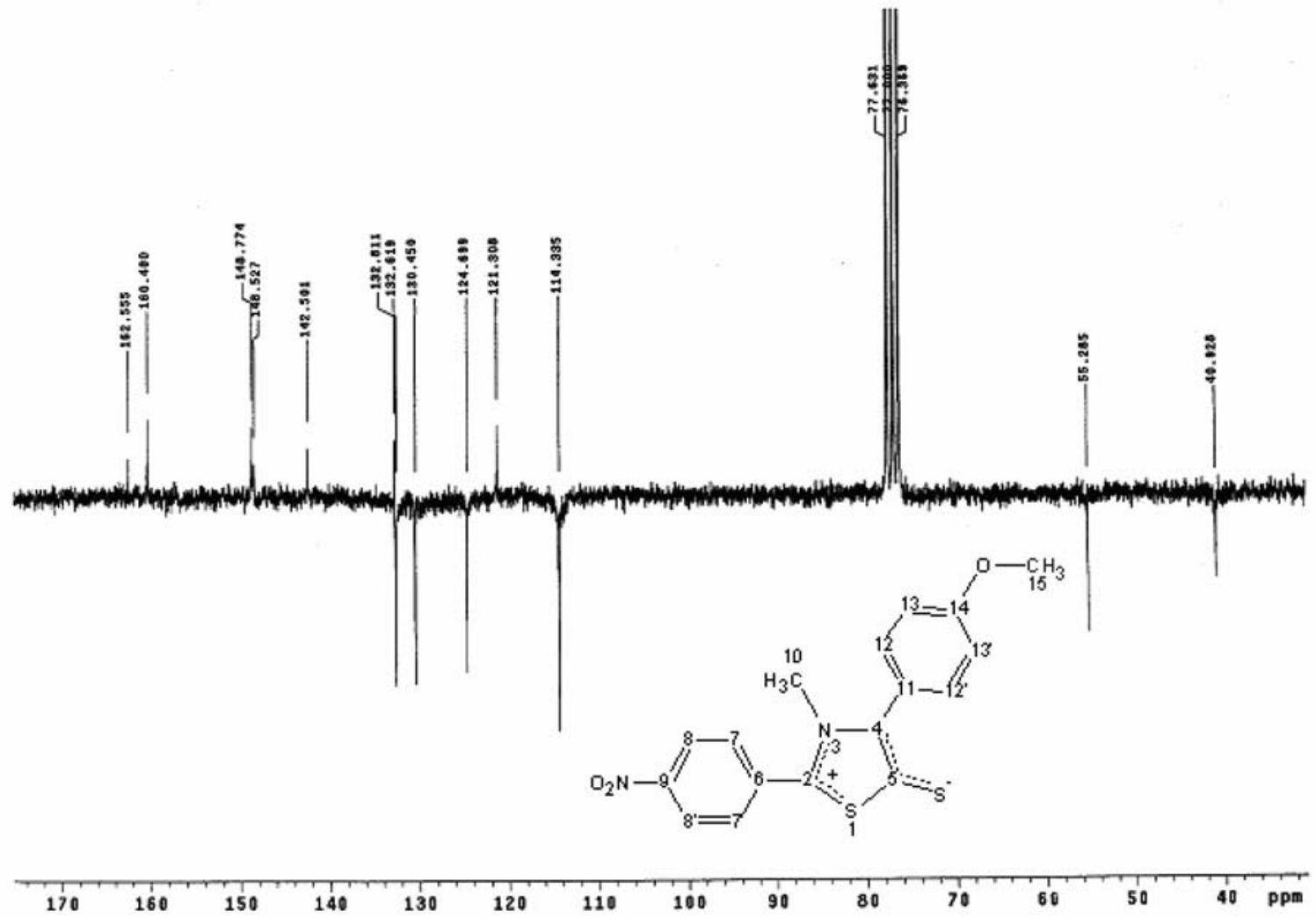

Figure S5. ${ }^{13} \mathrm{C}(\mathrm{APT}) \mathrm{NMR}$ spectrum for $\mathrm{MIC}-16\left(\mathrm{CDCl}_{3}, 50 \mathrm{MHz}\right)$. 


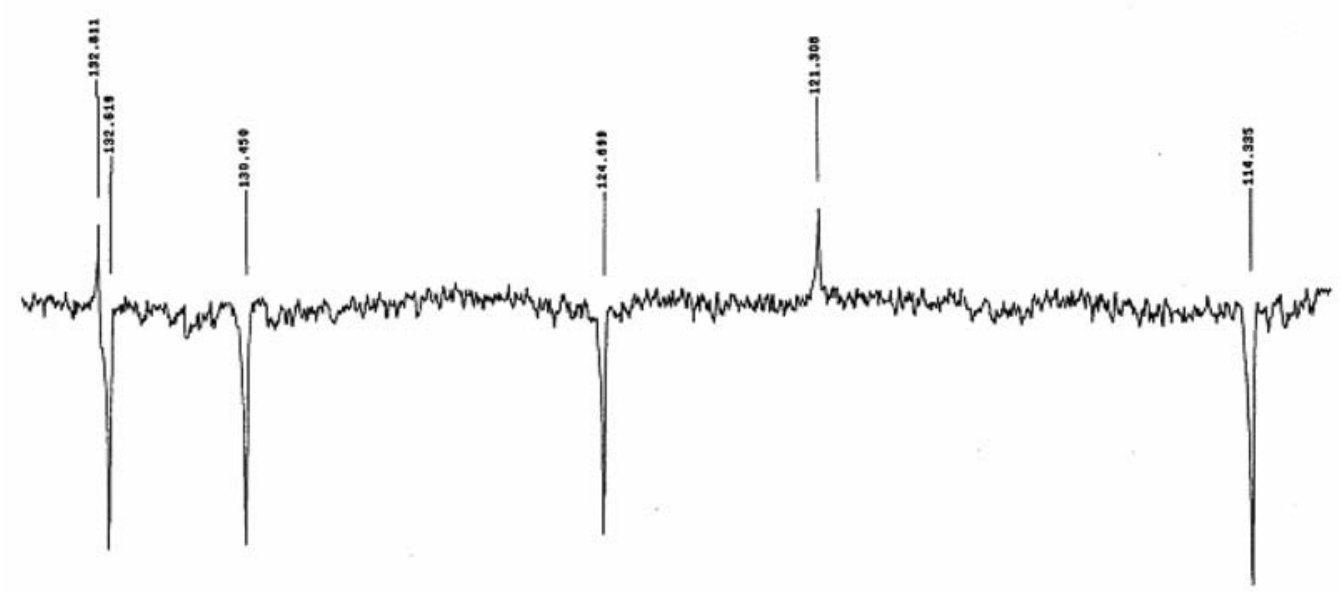

$\begin{array}{llllllllll}132 & 130 & 128 & 126 & 124 & 122 & 120 & 118 & 116 & \text { ppm }\end{array}$

Figure S6. Expanded version of ${ }^{13} \mathrm{C}(\mathrm{APT}) \mathrm{NMR}$ spectrum for $\mathrm{MIC}-16\left(\mathrm{CDCl}_{3}, 50 \mathrm{MHz}\right)$.

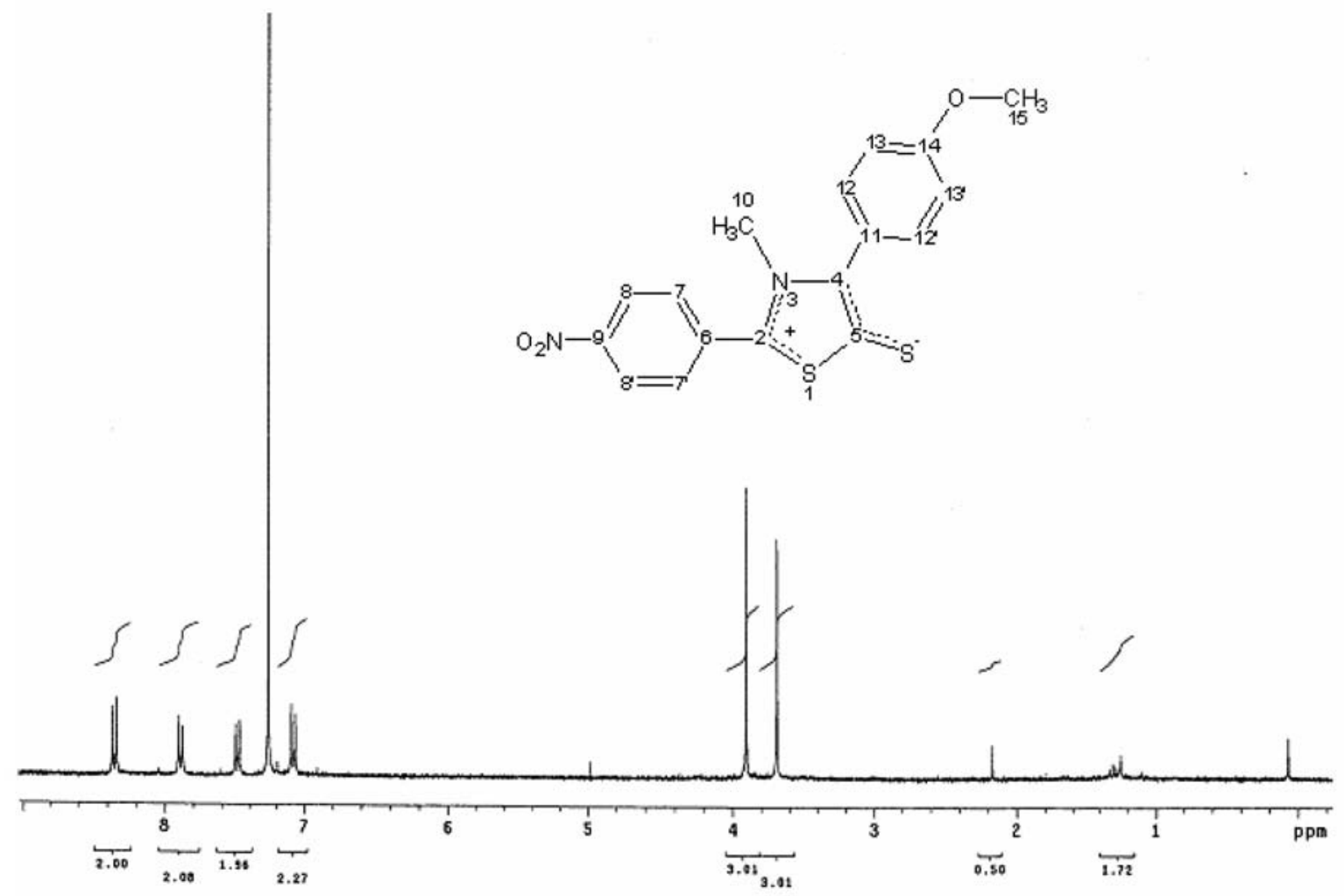

Figure S7. ${ }^{1} \mathrm{H}$ NMR spectrum for MIC-16 $\left(\mathrm{CDCl}_{3}, 200 \mathrm{MHz}\right)$. 


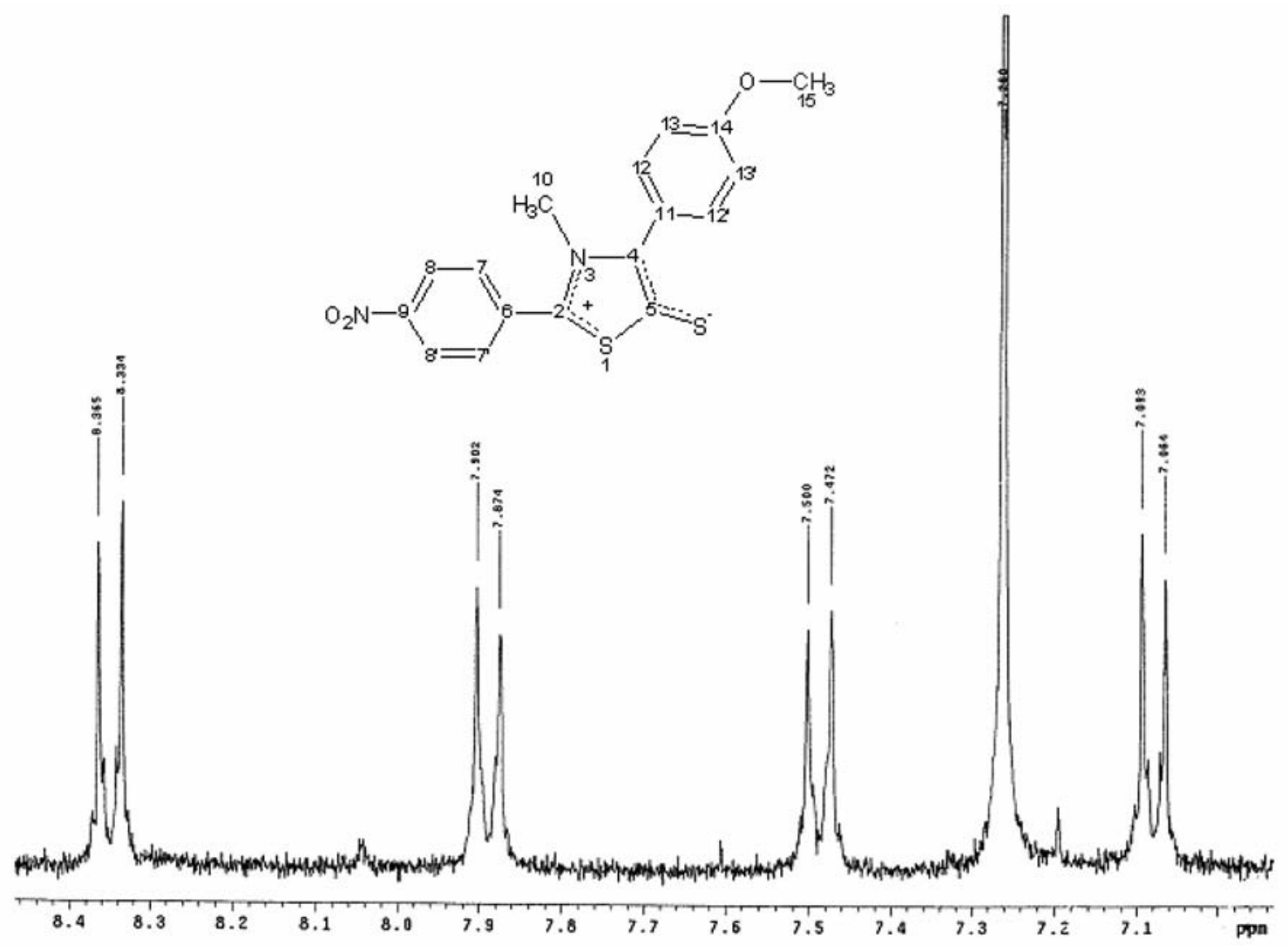

Figure S8. Expanded version of ${ }^{1} \mathrm{H}$ NMR spectrum for $\mathrm{MIC}-16\left(\mathrm{CDCl}_{3}, 200 \mathrm{MHz}\right)$. 